\title{
The Application of Computer Network and Information Technology in English Remote Education
}

\author{
HuaXin Xing ${ }^{1, a}$ \\ ${ }^{1}$ Environmental Management College of China, Qinhuangdao, Hebei, 066004, China \\ aqhdxhx@126.com
}

\begin{abstract}
Keywords: Computer Network, Information Technology, Remote Education
Abstract. With the fast development of education information, application of computer network and information techniques in teaching subjects is more and more common, and the English remote education is no exception. This paper firstly analyzes the necessity of the application of computer network and information technology, and then presents the advantages of them. Secondly, the concrete application methods of network and information technology in English remote education are given. Finally, application of cases proved that these methods have greatly promoted the development of English education, and achieved good results.
\end{abstract}

\section{Introduction}

With China's accession to WTO, China's opening up the pace gradually expanded, the traditional teaching idea has not adapt to the demand of personnel training, there must be a new breakthrough in the teaching idea, to reform the teaching mode, the old teaching methods. Digital living environment is being formed in twenty-first Century put forward a new proposition and challenge to our educational objectives, teaching content, teaching methods and means, open learning, lifelong learning, promote the diversification of the traditional teaching mode fundamentally change leather[1].

In today's information technology, learning theory and teaching theory of discipline development, has become the three pillar of the implementation of the theory of information technology and curriculum integration, expand the application of information technology driven from a micro macro oriented classroom curriculum level. Especially in the network and computer technology as the core of information technology has become an important engine for dissemination and application of knowledge, promote the profound changes of the hitherto unknown education industry[2].

Make use of modern teaching facilities, to improve the teaching quality as the goal, to get rid of the traditional way of learning knowledge, learning skills to focus, let students learn English language and English language learning practice, improve students' ability of using English, the reform of the teaching contents, teaching methods and teaching materials available, based on the new teaching system with personalized learning. Public English teaching reform of higher vocational education has become the inevitable trend of higher vocational education reform and development, to meet the needs of social development in twenty-first Century is to cultivate high-quality talents[3].

\section{What is Remote Education Network}

Remote Education Network Teaching Mode. Remote learning under the network environment in remote education by correspondence, radio and television, the use of computer network and multimedia technology, the third generation of teaching activities in the digital signal environment, known as the modern remote education[4]. This is an open concept, more precisely, network learning is advanced based on the concept, the use of cyber source, under the guidance of teachers, improve the students' autonomous learning, strengthen the teaching of teachers and students in the process of collaborative discussion.

The main form of dispersion (home) through the network, or CD via e-mail, BBS learning courseware, discussion, etc. in answering the students answer the questions[5]. Take a combination 
of two teaching mode of teaching form, which closely combined remote multimedia network teaching and traditional classroom teaching.

The Characteristics of Remote Education. The uniqueness of the long-remote network education determines the learning characteristics of network learning flexibility and interactivity. Network education flexibility is reflected in the reform of the teaching mode, learning that exceeded the limit of time and space, as long as access to the Internet, you can learn to accept the system, whenever and wherever possible, comprehensive education[6]. The learning characteristics of learning under network environment to reflect the interaction between the asynchronous interactive teaching information with the students, students and students, teachers and students, the instant, students can through computer networks to tutor questions, answer questions, to discuss a problem or collaborative learning among students, teachers can view every student the process of learning, and according to the learning situation of students, teaching plans and revise their teaching content.

Under the Support of Information Technology. Is the smallest unit of English Vocabulary Teaching in the teaching link? To improve the efficiency of vocabulary teaching, to make students in learning English listening, reading, writing, said a variety of abilities. The use of information technology in teaching vocabulary can realize the harmonious unification of autonomous learning and collaborative learning; also can realize the student-centered teaching mode. Basic skills and qualities which require teachers to learn and master modern educational technology should have changed the original concept of English vocabulary teaching.

Quickly grasp the ability and the ability of information processing information is to adapt to the requirement of development, increase the depth and breadth of teaching content, education resources rich, and education has broken the country and regional restrictions, but also to conform to the form of education, change the past single form of classroom teaching.

The Use of Information Technology Platform. Discuss and complete the task by BBS students. Extracurricular vocabulary teaching in the classroom is not enough for students to master vocabulary needed time. To master a word sound form meaning and usage, the students in the classroom learning is not enough, it is important to talk about after class and extracurricular tasks. BBS go with such a platform. Teachers can accord the amount of published posts to learn English vocabulary; students initiated the discussion or arrangement corresponding to the homework; let the students to participate in them. It can not only improve the enthusiasm of students to learn English vocabulary, but also can stimulate students' interest in English vocabulary learning.

Students can also through the mail to the teacher reaction meet their problems in learning or teaching, to make timely feedback. At the same time, because of the teachers on student performance and feedback can be kept confidential, so the student in the mail can speak freely, so as to ensure the effectiveness of communication between teachers and students. Through the E-mail, students can communicate with different countries and different regions of the English speaking or learning English, can not only expand their vocabulary, but also enhance the ability of application of English vocabulary in practice.

Theoretical Basis for Construction of Remote Network Classroom. According to constructivism, knowledge is not taught by teachers, but learners in certain contexts that the social and cultural background, with the help of the study is the knowledge acquisition process of other people (including teachers and learning partners) help, use the necessary learning materials, through meaning construction and. The theory and constructivist learning environment of Constructivism emphasizes student-centered learning, active construction change not only for students from passive recipients of external stimuli and knowledge object subject, information processing and knowledge meaning; the teachers are required to change from knowledge to teach, students to take the initiative to help students construct meaning person, promoter.

\section{How to Strengthen Construction of Remote Network Classroom}

Increase of Rich Learning Resources and Tools. Increase the supply of learning information, to meet the needs of learning content to the breadth and depth of the learners in the learning process. In 
addition to the basic curriculum content, should be timely provided to learner's abundant relevant learning resources and curriculum content. Secondly, should also be available for download and learn a variety of related software tools, such as electronic dictionary, audio and video player.

Prominent English Application Ability Raise and Training. Higher vocational education is to train applied talents, so in the teaching content teaching and training more outstanding practice part of. According to a survey of higher vocational students, learning interest is not the origin and theory itself, but by this theory can achieve the purpose and results. If the network in the course of using too much space to describe the knowledge content, while ignoring the practical part, easy to make the learners produce negative emotions, reduce the enthusiasm of learning.

Establish Correct Concept of Teaching Courseware. Courseware is an auxiliary means of teaching, is to learn the theory under the guidance of a certain teaching objectives according to the design, reflect some teaching strategies and teaching content of computer software. The introduction of English teaching multimedia courseware can most effectively with the process and characteristics of human cognition and language acquisition is a kind of learning theory of constructivism and teaching methods adapt to the environment. Excellent network courseware can help learner's smoothly autonomous learning. The courseware should be aimed at the emphasis and difficulties of understanding in the learning process in the use of multimedia, text, image, sound, animation, video, graphic charts and other multi-dimensional performance given clear instructions. Of course, you want to make a good courseware, need to spend considerable time and effort to obtain relevant information, which requires teachers to set up correct concept based on recognition of modern education, and carry out to persevere.

The Update Mode of Learning Classroom. In the network environment, students' Autonomous earning under the guidance of teachers, students' thirst for knowledge of human-computer interaction are met quickly, massive resources let students view fully extended, a new network learning model is formed, as shown in Fig. 1.

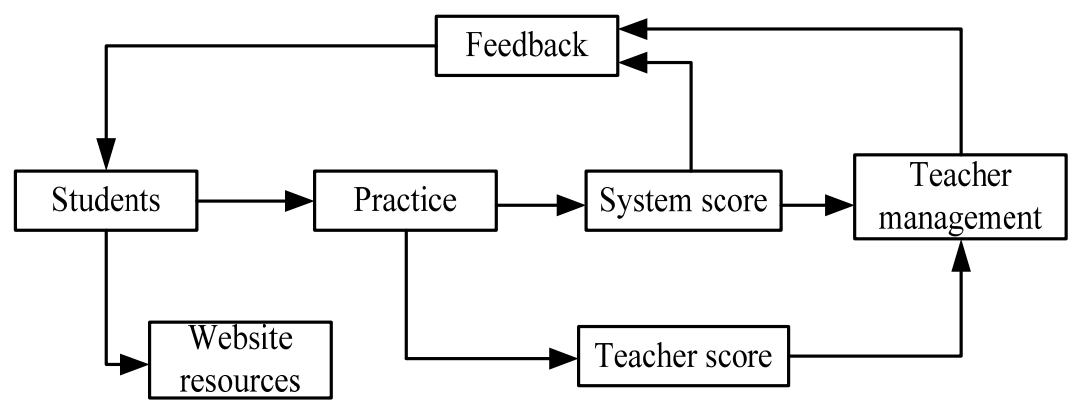

Fig. 1. Learning mode schematic

This network course is integrated with listening, reading and writing skills as training complement classroom teaching and Extracurricular Autonomous Learning, and students' independent thinking and team activities, improve their comprehensive English ability, learning ability and communication skills.

\section{System Function Realization}

Curriculum Training Module. In order to realize the curriculum training module, design the professional course training, professional technical training and basic knowledge training. Each class of processing methods and display methods are very different. In the professional course training view class, the design of the curriculum level, curriculum categories, curriculum materials selection method, the system through these content to obtain the accurate teaching information, the system inquires the corresponding teaching content generation to study the curriculum to display to the user. In the professional course training, the design of teaching content, focus and difficulty, the exercise of the three columns, in the teaching content for video playback and synchronization of the content of 
PPT, the key points in the design of the content of the key and difficult analysis. Speaking in the fine exercises system provides for the content of the representative exercises for intensive analysis.

Professional and technical training class design technology, technical level for users to choose, the system based on user input generated content, the teaching content in the class view page design, the classic questions two columns, teaching content to provide users with video content, the classic questions to provide users with the classic test questions, but this part of the system has the resources to design, so for very professional knowledge and no explanation. The training of basic knowledge of four levels: elementary school, junior high school, high school, vocational teaching plan is designed, which for each level design different training content, mainly for national and Liaoning Province syllabus design of column, as the user provides teaching content design, teaching design and teaching design and multiple functions.

Teaching Method Module. Teaching method training is to provide users with teaching methods and research content, in the module design of teaching theory and teaching method application demonstration, including teaching theory training of view page design teaching theory, teaching two columns. The teaching method theory provides the teaching material of the teaching method, the teaching method and the teaching method of the teaching method. View interface design of teaching method is applied to the teaching of teaching method and teaching application of two functions. The application of the teaching method provides a detailed analysis of the use of the teaching method, and provides a detailed guidance for the user.

\section{Conclusion}

Remote network teaching has strong interactivity, change education for individual, make it rigidly uniform teaching to teach students in accordance with their aptitude, learning to learn at their own pace, in the right place at the right time to learn, to achieve a variety of communication and interaction between students and computers, students and students, students and teachers, teachers and students to provide to achieve the best teaching and learning environment of constructivism, is the mainstream education mode in the future.

\section{References}

[1] X. Y. Li. To Activate the Motivation of Autonomous learning of Remote Learners, Chinese Remote Education, Vol. 23(2013), p. 31-33.

[2] M. Cao. The Monitoring of Network Learning, Chinese Remote Education, Vol. 22(2012), p. 47-49.

[3] X. F. Cai. Study English multimedia network teaching interactive principle and University, Journal of Xi'an College of Foreign Languages, Vol. 13(2014), p.70-74.

[4] S. Q. Lv. On Construction of Multimedia Resources In Distance Education, China Information Technology Education, Vol. 15(2015), p.205-206

[5] X. Yang. Teaching Research of Distance Education System Based on Internet, Information System Engineering, Vol. 11(2012), p.157-158

[6] L. F. Yang. Research On the Application of Virtual Reality Technology In Distance Education, Intelligence, Vol. 12(2015), p.17-18. 